\title{
Accidental Injuries Caused by Automotive Frontal Collision
}

\section{Karen Viviana Pérez Luján ${ }^{a}$ (D), Rita de Cassia Silva ${ }^{a}$ (D) , Alessandro Borges de Souza Oliveira ${ }^{\text {(D) }}$, Diego Antonio Legarda Cordobab (D), Palloma Vieira Muterlle ${ }^{a}$ (i) , José Alexander Araújo ${ }^{a}$ (D), Jorge Luiz de Almeida Ferreira ${ }^{a}$ (1) , Cosme Roberto Moreira da Silva $^{a^{*}}$ (1)}

\author{
a Universidade de Brasília, Departamento de Engenharia Mecânica, Brasília, Brasil. E-mails: kperezlujan@gmail.com, \\ ritasilva.fga.unb@gmail.com, abso.faculdadeunbgama@gmail.com, pmuterlle@gmail.com, jaunb@gmail.com, jorge@unb.br, \\ cosmeroberto@gmail.com \\ ${ }^{\text {b } C o r p o r a c i o ́ n ~ U n i v e r s i t a r i a ~ U n i c o m f a c a u c a, ~ P o p a y a ́ n, ~ C a u c a, ~ C o l o ̂ m b i a . ~ E-m a i l: ~ l e g a r d a 8027 @ g m a i l . c o m ~}$ \\ ${ }^{*}$ Corresponding author
}

https://doi.org/10.1590/1679-78256256

\begin{abstract}
This study aimed to use a simulated vehicle to asses quantitatively the head and neck injuries of the occupants, in a frontal car crash, when the driver has only one hand on the steering wheel, such as while using a cell phone when driving. First, we conducted a survey of NHTSA reports on real laboratory tests of frontal collisions involving sedans. The effects of these collisions on the neck of a Hybrid III $50^{\text {th }}$ percentile male crash test dummy were measured in terms of average head acceleration and force along the $X, Z$, and $Y$-axes. These acceleration, force and torque values obtained from the NHTSA database were used to validate the simulated model. The results obtained were compared with case $\mathrm{E}$, the standard dummy position used in frontal collision tests. The results obtained in the simulation of the four cases of driving with only one hand demonstrate a probability of more than $67 \%$ that the driver will sustain AIS+2 injuries during a frontal crash. In all the cases, the skull fracture percentage was the most representative, occurring between 89 and $94 \%$ of cases where the driver had only one hand on the steering wheel.
\end{abstract}

\section{Keywords}

Crash Test, Automotive, Accident

\section{Graphical Abstract}

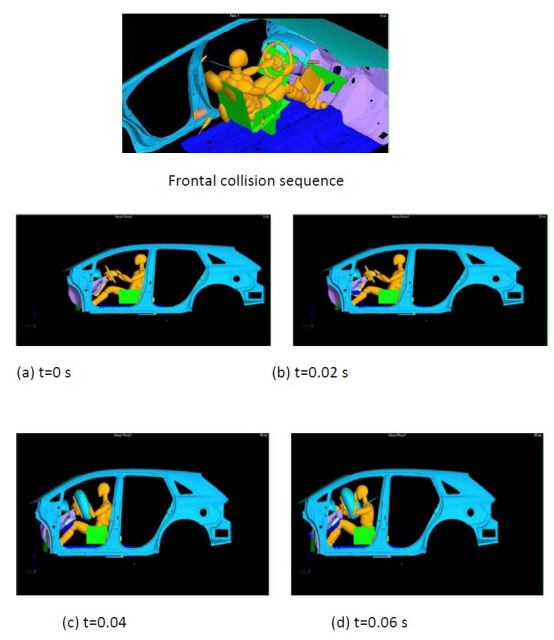

Received: September 09, 2020. In Revised Form: November 06, 2020. Accepted: November 06, 2020. Available online: November $09,2020$. https://doi.org/10.1590/1679-78256256

(1) Latin American Journal of Solids and Structures. ISSN 1679-7825. Copyright @ 2020. This is an Open Access article distributed under the terms of the Creative Commons Attribution License, which permits unrestricted use, distribution, and reproduction in any medium, provided the original work is properly cited. 


\section{1 - Introduction}

Recent decades have seen a significant increase in the number of frontal car accidents and resulting injuries. As such, manufacturers seek to incorporate a wide range of safety features into their cars to enhance passenger safety, including side and rear airbags, energy-absorbing steering columns, and side-door impact beams, among others [1].

However, a car accident involves a number of factors, such as human error, condition of the vehicle and the physical and social surroundings [2], [3]. According to [4], the human factor accounts for $90 \%$ of car accidents. One widely studied cause of car accidents is driver behavior, primarily overconfidence and engaging in unnecessary activities while driving, which can distract them and significantly impair their ability to operate a motor vehicle [5]. Reaching for an object, tuning the radio, eating, drinking, handling electronic devices such as cell phones, GPS units, and tablets, among others can divert a driver's attention and compromise their ability to react and avoid a collision [6]. These unnecessary distractions are a major risk for collision, since they can cause cognitive failure, driving errors and traffic violations such as driving with one hand long enough to have tragic consequences [7].

Several criteria have been established to estimate injury levels in frontal collisions. Among the parameters used to assess car occupants' responses to impact are acceleration, force and torque, which are used in biomechanical field studies[8]. Distinct criteria were proposed for different body regions to assess their severity in automobile accidents [9], such as the head injury criterion (HIC) [10], which is based on head acceleration during a collision.

There are direct and indirect approaches to study the responses of occupants and injury criteria in car accidents. The direct approach involves real collision tests, using crash test dummies [11], denominated anthropometric test devices (ATD), which are standard in vehicle crash tests [8]. These highly durable devices are useful in simulating human dynamic responses. The dummies are programmed to record dynamic behavior data in car crash tests. They are frequently used to help establish injure criteria in order to assess the efficacy of passenger protection systems. ATDs are also used to study head trauma caused by direct impact in martial arts. Mcintosh et al. [12] studied dynamic head responses of the Hybrid III dummy with and without a helmet, in order to reduce the risk of concussion and brain injuries during boxing matches and training.

The indirect approach uses a computer simulator, where the dynamic responses of the vehicle simulated in crash tests are used to evaluate their performance in impacts or assess new passenger safety systems [13]. Since it is impossible to study all crash scenarios via physical tests, computer simulations using software such as Pam Crash, LS DYNA and MADYMO supply data essential to assessing car performance in the crash test [14]. Dynamic modeling of these performances using finite elements and multibodies [15] provide essential tools for investigating and analyzing the dynamic behavior of vehicle occupants and the injuries sustained. Zhang et. al [16] assessed the potential risks of injuries to backseat passengers, using a frontal impact model simulated in MADYMO software. N. Li [13] determined chest response in steering wheel impacts during frontal collisions of heavy vehicles, in order to improve their safety systems.

Increasingly reliable simulation models of vehicles and occupants under different crash conditions were established by Fairlie and Steenbrink [17], where simulation tools were used in dynamic fluid techniques to accurately model the internal volume of an airbag and, together with the MADYMO airbag models, produce more accurate results of passenger-airbag interaction. Other studies, such as that by Panzer et al. [18], demonstrate that simulated models of the spine can be developed at the tissue level to provide a model with high biofidelity for injury prediction in car accident scenarios. Complete models of the vehicle and occupant have been simulated [19], assessed and validated, with accurate injury prediction, thereby contributing to improving passenger protection.

Other studies, such as that by Luo et al. [20], focused on the effectiveness and improvements of safety systems, where the benefits of seatbelt pretensioners in braking maneuvers before impact were confirmed, compared to their 3point counterparts. The study was conducted to analyze a MADYMO model. Recent study [21] carried out a finite element evaluation to identify the injury levels to a 1.5 years old child dummy accommodated on a seat under variable angles $\left(15^{\circ}, 30^{\circ}\right.$, and $\left.45^{\circ}\right)$, in a typical car crash of $47 \mathrm{~km} / \mathrm{h}$. The results allowed to understand the seat angle role in injury to the child head. It was observed that the seating angle of $45^{\circ}$ can minimize the acceleration and displacement in the head of the child compared to the $15^{\circ}$ and $30^{\circ}$. The results can be used to minimize the injury to children body during car accident. Most of the existing dummies and models are based on the male body. A recent paper [22] developed a model representing a small female. The anthropometry of both models has been derived from the RAMSIS anthropometry database. Joint properties for the mid size male were derived from literature, and established scaling techniques were employed to derive joint properties for the small female model. This female model was validated using scaled biofidelity requirements from the literature and biomechanic data of the applicable body size including side airbag loading. The models were found to satisfy the available biofidelity requirements in terms of kinematics, chest deflections, and accelerations 
The results may prompt the implementation of advanced systems with greater safety potential in vehicles. Many of these models and a broad database of experimental crash tests are available from government agencies such as the National Highway Traffic Safety Administration (NHTSA). A number of the models developed by National Crash Analysis Center (NCAP) researchers have been used to study guardrail strength flaws and are available to the public [23].

The human body is a highly complex biological and physical system. By applying the fundamentals of the multibody dynamics theory, the human body can be simulated as a series of rigid segments connected to different types of joints. The resulting mathematical model can be described by systems of differential equations of non-linear movement [24]. Several investigators have used these human models to simulate crashes [25]. In the present study we used MADYMO to analyze frontal collisions for four cases in which the driver had only one hand on the steering wheel. Based on the simulation results obtained, assessments were made from a crash dynamics standpoint, using head and neck injury criteria to evaluate the severity of the injuries sustained by the driver when steering the vehicle with only one hand, at positions A, B, C and D, as described in the "Methodology section".

\section{2- Methodology}

The NHTSA database of real frontal crash tests from the New Car Assessment Program (NCAP) was searched. These data were used as input for a simulated model. The use of computational simulations allows evaluations of several different situations of car crash event, and enable analysis of biomechanical response during collisions [26].

A multibody model and MADYMO software were used in this study. The model contains passive safety systems for the Hybrid III $50^{\text {th }}$ percentile dummy. The aim of the study was to assess the risk of injury to the driver, using the dummy to simulate four potentially dangerous driving positions with one hand on the steering wheel.

\section{1 - Description of Simulation Models}

The MADYMO program is widely used in vehicle and passenger restraint systems due to its different types of dummies and rapid simulation processing [8]. The 2013 Toyota Venza was selected to simulate a frontal collision because of its reliable response in experimental tests. This model is made of finite element components, with similar external dimensions, type of car and weight. The model consists of the following components: The Hybrid III $50^{\text {th }}$ percentile male crash test dummy based on multibody models, due to its greater ability in determining injury level from a frontal collision, a three-point seatbelt, airbag and safety cage in finite elements. The Hybrid III $50^{\text {th }}$ percentile male dummy was obtained in the section of database and software of NHTSA official site [23]. Figure 1 shows the simulation model.

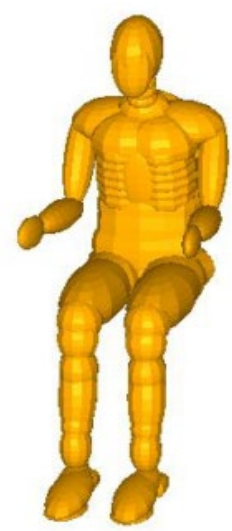

Figure 1 Male, ellipsoid Hybrid III $50^{\text {th }}$ percentile model

Dummy position - Frontal crash tests standards developed by NCAP were used in this work. In this case the dummy was positioned inside the vehicle with the elements "INITIAL.JOINT_POS" of software MADYMO [27,28].

The airbag-hand and hand-head contacts were established using the XMADgic tool of the MADYMO program, applying contact functions and fixed values for the strength coefficient between the surfaces [28 - 31].

Considering the hand position on the steering wheel, a relation was established between these positions and the numbers of a watch face. For comparative reference, the right hand remained between the 2 and 3 o'clock position and the left position between 9 and 10 o'clock as depicted at figure 2. These positions were selected for more effective control of the steering wheel. 


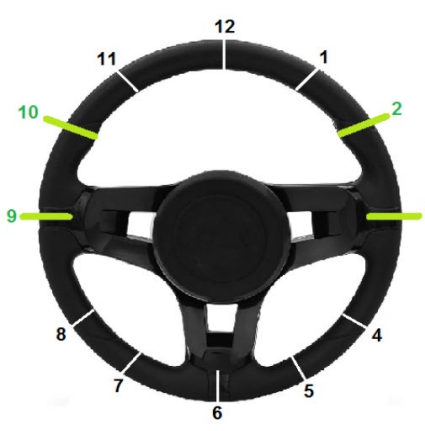

(a)

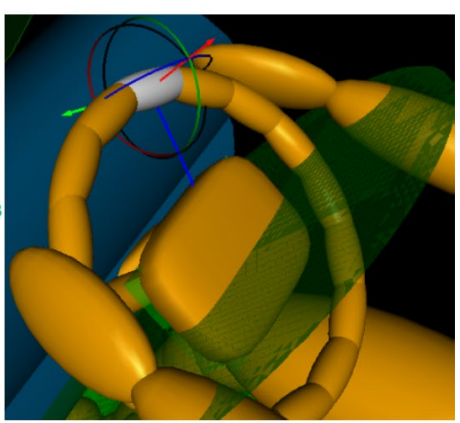

(b)

Figure 2 a) Ideal hand position on the steering wheel (between 2 and 3 o'clock for the right hand and 9 and 10 o'clock for the left. b) Hand position of the dummy using the MADYMO program (position E), according to the interval established.

These positions were defined as "Case A, B, C and D" and "Case E", the latter representing the standard position in a frontal collision. The positions of the dummy were as follows:

- Dummy case A- The driver steers with the right hand positioned between 2 and 3 o'clock. The left hand remains near the horn at the center of the steering wheel.

- Dummy case B -The driver steers with the left hand between 2 and 3 o'clock, with the right hand off the steering wheel.

- Dummy case $\mathrm{C}$-The driver steers with the right hand between 9 and 10 o'clock, with the left hand off the steering wheel.

- Dummy case D -The driver steers with the left hand between 2 and 3 o'clock, with the right hand off the steering wheel.

- Dummy case E - The driver steers with both hands in the standard position used in real frontal crash tests, that is, the left hand between 9 and 10 o'clock and right hand between 2 and 3 o'clock.

The first part of this study assesses the frontal collision test data of a number of vehicles, available in the NHTSA database. Next, the simulated vehicle was used to evaluate dummy data generated during the frontal crash, at positions A, B, C, D and E. Finally, head and neck injury criteria were calculated and analyzed at each of the dummy positions.

\section{2 - Injury Criteria}

The Federal Motor Vehicle Safety Standard 208 (FMVSS 208) is administrated by National Highway Traffic Safety Administration (NHTSA) and specifies performance requirements for anthropomorphic test dummies in the front outboard seats of passenger cars, including the active and passive restraint systems. It aims to reduce the number of fatalities and severity of injuries of occupants involved in frontal crash [32].This Project evaluates obtained results for HIC (Head Injury Criterion) and Nij (Neck Injury Criterion), described as follows.

\subsection{1 - Head injury}

The resulting head acceleration during frontal impact was used to calculate the HIC (Head Injury Criterion) value. $\mathrm{HIC}$ is associated with risks of injury caused by direct impact of the driver's head with some component of the vehicle's interior [33]. The resulting head acceleration during frontal impact was used to determine HIC. The magnitude and duration of acceleration [34] was used, as shown in Equation 1:

$H I C_{15}=\max \left\{\left(\frac{1}{t_{2}-t_{1}} \int_{t_{1}}^{t_{2}} a(t) d t\right)^{2.5}\left(t_{2}-t_{1}\right)\right\}$

where $a$ represents head acceleration in $g, t_{1}$ time at initial impact and $t_{2}$ end of impact, in milliseconds. A 15 milliseconds interval was used to calculate HIC. Most of the time intervals associated with head impacts that produced brain damage or skull fracture are less than 10 milliseconds [35]. 
In the present study, the head injury value was used to estimate the likelihood of death or risk of injury. The formulas to estimate the likelihood of injury, associated with $\mathrm{HIC}_{15}$, were proposed by Prasad and Mertz [35]. Injury level is classified by the Abbreviated Injury Scale (AIS) using a 1-6 scale. The NHTSA [9] has used Equations 2-5 to calculate injury probability $(p)$, depending on the severity level (HIC), as follows:

$p(A I S+2)=\frac{1}{1+e^{2.49+140 / H I C-0.0069 * H I C}}$

$p(A I S+3)=\frac{1}{1+e^{3.39+140 / H I C-0.00531 * H I C}}$

$p(A I S+4)=\frac{1}{1+e^{4.9+140 / H I C-0.00501 * H I C}}$

$p(A I S+5)=\frac{1}{1+e^{7.82+140 / H I C-0.00613 * H I C}}$

Vander Vost et al. [36] proposed a new head injury index, which relates speed variation in the time interval measured by the HIC with the skull fracture correlate (SFC), as defined in Equation 6.

$S F C=\frac{\Delta V_{H I C}}{\Delta T_{H I C}}$

where:

$\Delta V_{H I C}=\int_{t_{1}}^{t_{2}} a d t$

and

$\Delta T_{H I C}=\left(t_{2}-t_{1}\right)$

Chan et al. [37] developed a generalized linear skull fracture criterion correlated with the SFC. Equation 9 represents this correlation, where $\mathrm{P}$ is the probability of fracture.

$\ln \left(\frac{P}{1-P}\right)=6.39 * \ln (S F C)-32.53$

\subsection{2 - Neck injury}

The neck injury criterion $\left(\mathrm{N}_{\mathrm{ij}}\right)$ used in this study is a combination of axial forces tension/compression at the neck and the flexion/extension moment, with four types of injury criteria: tension-extension, tension-flexion, compressionextension and compression-flexion. $\mathrm{N}_{\mathrm{ij}}$ is the sum of normalized axial force on the neck and the normalized neck moment in the occipital condyle, according to Equation 10:

$N_{i j}=\frac{F_{z}}{F_{z c}}+\frac{M_{o c y}}{M_{y c}}$

where $\mathrm{Fz}$ is the axial force of tension/compression on the neck, Fzc the critical value of neck axial force, Mocy the total moment at the occipital condyle of the neck and $M_{y c}$ the critical value of the neck bending moment. The value of $N_{i j}$ cannot exceed 1.0 at any point in time according to the NHTSA proposal [38].

The formula to calculate probability of neck injury is similar to that used for head injury. Depending on the severity level, equations 11-14 are used to calculate neck injury:

$$
\begin{aligned}
& p(A I S+2)=\frac{1}{1+e^{2.054-1.195 N_{i j}}} \\
& p(A I S+3)=\frac{1}{1+e^{3.227-1.969 N_{i j}}}
\end{aligned}
$$




$$
\begin{aligned}
& p(A I S+4)=\frac{1}{1+e^{2.693-1.195 N_{i j}}} \\
& p(A I S+4)=\frac{1}{1+e^{3.817-1.195 N_{i j}}}
\end{aligned}
$$

\section{Model validation}

\subsection{First validation}

The frontal crash test primarily measures the constraint systems used to protect the driver and passengers [39]. In this article, the simulated tests involve a frontal collision against a perpendicular (full-width) rigid barrier at $56 \mathrm{~km} / \mathrm{h}$. The deceleration experienced by the vehicle in the experimental test was used as an input parameter in the simulation (Figure 3) to obtain overall vehicle behavior during impact [8] [40]. The minimum pulse is $-54 \mathrm{~g}$, with a duration of $200 \mathrm{~ms}$. The simulation shows the dummy's response during the crash. Thus, the output signal provides accurate dummy movements for the frontal collision. The dynamics of the dummy were obtained using sensors to assess the potential risk of injury to the occupant.

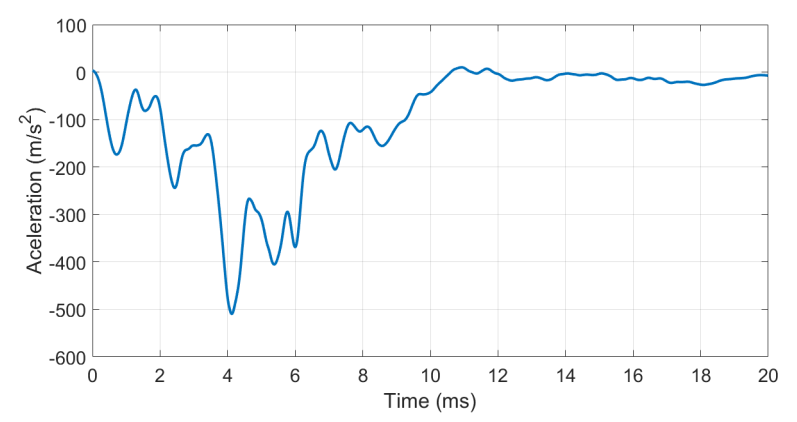

Figure 3 Acceleration pulse used for the model.

This project included a preliminary study of sedans, since they are the most common cars on the market and the most widely used in experimental tests available in the NHTSA databases [23]. The present study used the data from the new car assessment program (NCAP) tests, involving the Hybrid III $50^{\text {th }}$ percentile dummy, at a speed of $56 \mathrm{~km} / \mathrm{h}$. The responses of vehicles and drivers in frontal collision tests using 2009 and 2016 models were selected.

Figures 4-6 show the results of the first validation for the model selected. In figure 4, comparison between simulated head acceleration (dotted line) and the experimental curves from the NHTSA database (upper and lower solid lines) reveal that the dummy responses are within the experimental range for a collision. This is extremely important because temporal behavior and maximum and minimum global values are used for subsequent analysis of head and neck injuries.

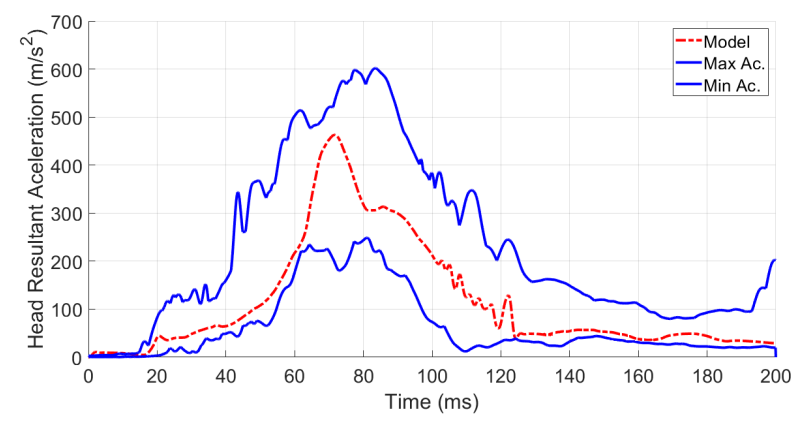

Figure 4 Results obtained in the MADYMO simulation (dotted line) and the range with maximum (upper line) and minimum (lower line) acceleration values in the NHTSA experimental head acceleration tests.

The Figure 5 shows the results of the simulation and the experimental tests of force along the X-axis of the neck of the dummy. 




Figure 5 Results obtained in the MADYMO simulation (dotted line) and the range of NHTSA experimental tests for force along the Xaxis of the neck (solid lines).

Figures 6 and 7 show the curves obtained for force along the Z-axis and torque along the Y-axis of the neck, respectively.

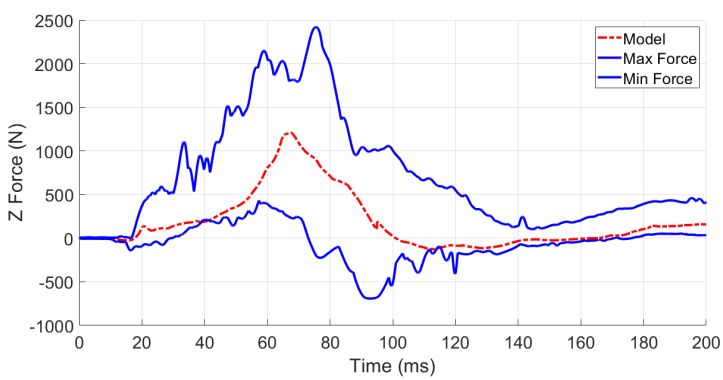

Figure 6 Results obtained in the MADYMO simulation and the range of NHTSA experimental tests for force along the Z-axis of the neck.

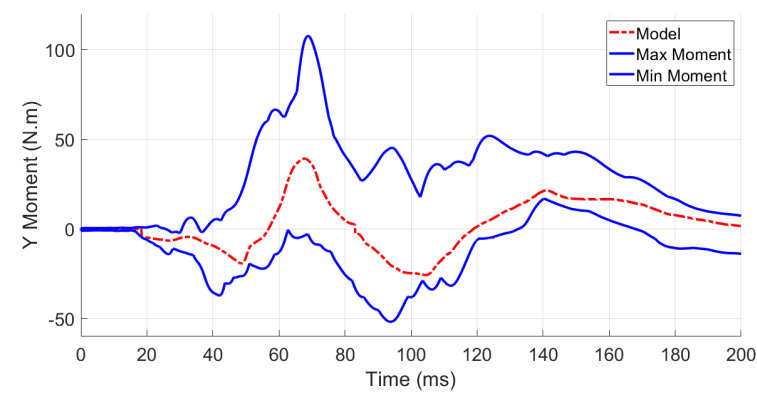

Figure 7 Results obtained in the MADYMO simulation and the range of NHTSA experimental tests for the bending moment along the Y-axis of the neck.

\section{2 - Second validation:}

A second validation of the model was conducted. In this case, the responses simulated in the vehicle were compared with a standard NCAP experimental crash test conducted by NHTSA ((NHTSA \#7969) in a 2013 Toyota Venza Sedan, using Hybrid III as occupants in the front seats. This vehicle was selected in order to better understand the capacity of the simulated model to predict collision responses. The simulation model developed for MADYMO in 2013 [23] used in the present study contains the structure of the selected vehicle, with a number of updates to the interior.

\section{4 - Frontal impact simulation}

After this model validation phase, the simulations were conducted for both the vehicle and occupant response. The responses of the simulated vehicle for head acceleration, forces and torque were represented graphically, along with those of the NHTSA tests for quantitative comparison purposes.

Figure 8 shows that the simulated curves exhibit behavior very similar to that of the real test. The maximum value for force along the $\mathrm{x}$-axis differs slightly, but shows similar response time. This is partly due to the lack of a passenger in the back of the vehicle, which would add inertia to the model and reduce acceleration. 


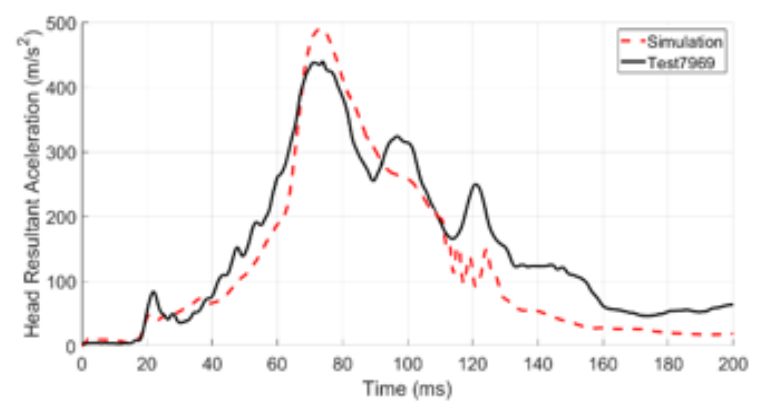

(a) Head Acceleration

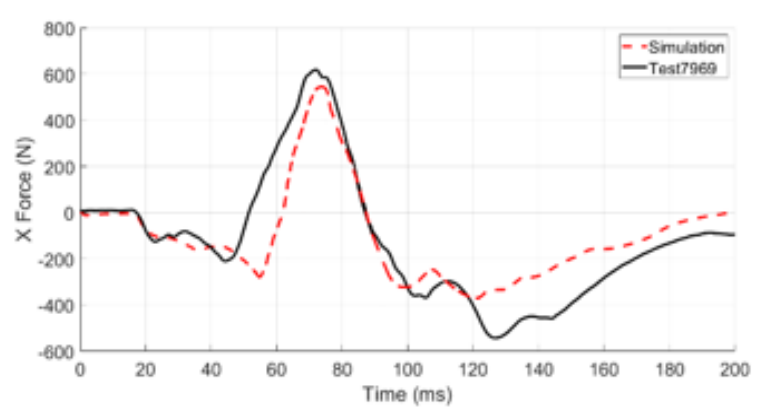

(b) Force along the $\mathrm{X}$-axis of the neck

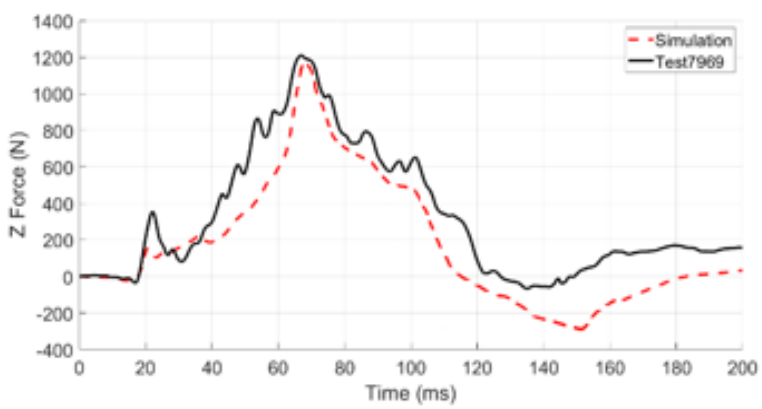

(c) Force along the Z-axis of the neck

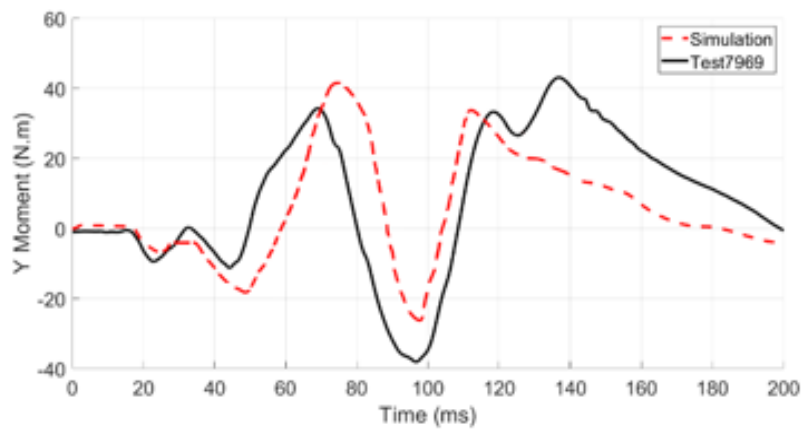

(d) Torque along the $\mathrm{Y}$-axis of the neck

Figure 8 Comparison of the results obtained in the MADYMO simulation (dotted lines) and real NHTSA test results for the model (solid lines). 
The Objective Rating tool of the MADYMO program was used to numerically compare the curves, where the simulated response values were compared with each experimental response. The global maximum and minimum response times of the functions are correlated using classification and association methods. This tool makes it possible to obtain percentage correlation indices between GMaxV (Global Max Value) values, which represent the global maximum value in the function. GMaxT (Global Max Time) is the time at which the maximum global value is obtained. GMinV (Global Min Value) is the minimum global value of the function and GMinT (Global Min Time) the time at which the minimum global value is obtained [31], indicating which high or low correlation has simulated responses in relation to its experimental counterparts.

Table 1 presents the correlation indices between the simulation responses and reference test. Head acceleration exhibits high correlation in the maximum global index. This indicator considers the simulation as valid for calculating damage criteria, because they use the maximum response values.

Table 1 Correlation index between the simulation responses and reference test.

\begin{tabular}{ccccc}
\hline & GMaxV\% & GMaxT\% & GMinV\% & GMinT\% \\
\hline Head Acceleration & 93.07 & 97.02 & 0.07 & 100 \\
\hline X Force & 82.55 & 95.88 & 77.03 & 74.57 \\
\hline Z Force & 99.84 & 99.41 & 27.42 & 95.63 \\
\hline Y Moment & 91.04 & 76.80 & 90.76 & 93.60 \\
\hline
\end{tabular}

Given the high correlation percentages between the simulation and experimental test results for maximum and minimum global values and temporal behavior, the head injury $\left(\mathrm{HIC}_{15}\right)$ and neck $\left(\mathrm{N}_{\mathrm{ij}}\right)$ criteria of the model were calculated. The simulation results were then compared with the experimental values (Table 2 ).

Table 2 Comparison between experimental $\mathrm{HIC}_{15}$ and $\mathrm{N}_{\mathrm{ij}}$ criteria from the NHTSA database and those calculated for the model.

\begin{tabular}{ccccc}
\hline & \multicolumn{2}{c}{ Head Injury Criterion $\left(\mathrm{HIC}_{15}\right)$} & \multicolumn{2}{c}{ Neck Injury Criterion $\left(\mathrm{N}_{\mathrm{ij}}\right)$} \\
& Experimental Result & Simulation Result & Experimental Result & Simulation Result \\
\hline Model & 167 & 168 & 0.34 & 0.40 \\
\hline
\end{tabular}

The simulation developed in the present study can adequately simulate head acceleration, in addition to forces and torque on the neck. Suitable equations can also be used to analyze the resulting injuries to vehicle occupants based on the study criteria.

\section{5 - Simulation and Results}

This study aimed at assessing potential crash test dummy head and neck injuries in a frontal collision, for 4 positions where the driver steers with only one hand. Figure 9 shows an upper view of the driver at the four established positions, before impact (A, B, C and D). The simulations are based on these positions.

The sequence of images in Figure 10 shows the simulation results for case $A$ with a 20 ms difference between images. Figure 10 (c) depicts the moment of maximum frontal impact.

In order to compare the injuries caused in a frontal crash when the driver is steering with only one hand, figures 11 and 12 present the probability of head injury as a function of $\mathrm{HIC}_{15}$ (Fig. 11) and the probability of skull fracture as a function of the skull fracture correlate (SFC) (Fig. 12) for each of the positions (A, B, C, D and E).

Figure 11 depicts the probability of head injury as a function of $\mathrm{HIC}_{15}$, for AIS+2 and AIS+3, in all the cases proposed (A, B, C, D and E).

Figure 12 demonstrates the probability of skull fracture as a function of the skull fracture correlate (SFC), for cases $A, B, C, D$ and $E$. In this case, we used equation 9, which establishes the linear correlation between the probability of fracture $(P)$ and a generalized skull fracture correlate (SFC). 


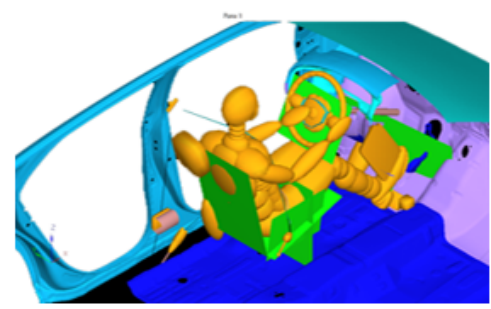

(a) Case A The driver steers with the right hand positioned between 2 and 3 o'clock. The left hand remains near the horn at the center of the steering wheel.

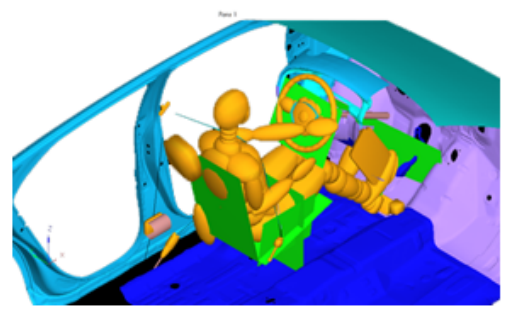

(b) Case B The driver steers with the left hand between 2 and 3 o'clock, with the right hand off the steering wheel.



(c) Case $\mathbf{C}$ The driver steers with the right hand between 9 and 10 o'clock, with the left hand off the steering wheel.

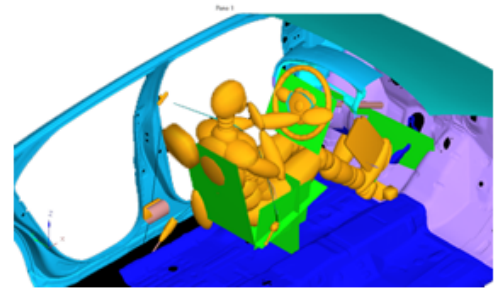

(d) Case D The driver steers with the left hand between 2 and 3 o'clock, with the right hand off the steering wheel.

Figure 9 Upper view of the model at the 4 cases initial positions.

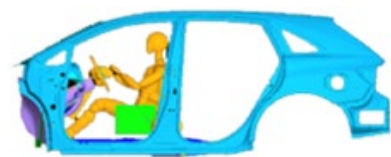

(a) $\mathrm{t}=0 \mathrm{~ms}$



(c) $\mathrm{t}=40 \mathrm{~ms}$

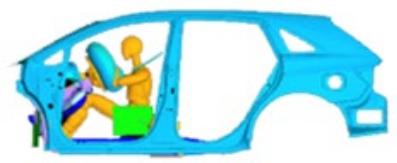

(e) $\mathrm{t}=80 \mathrm{~ms}$



(b) $\mathrm{t}=20 \mathrm{~ms}$

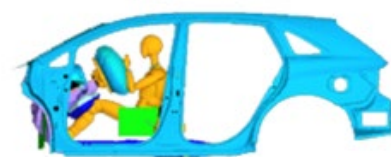

(d) $\mathrm{t}=60 \mathrm{~ms}$

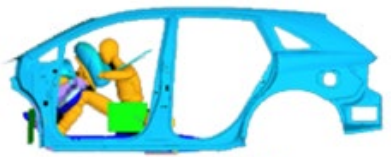

(f) $\mathrm{t}=100 \mathrm{~ms}$

Figure 10 Frontal collision sequence for case A. 


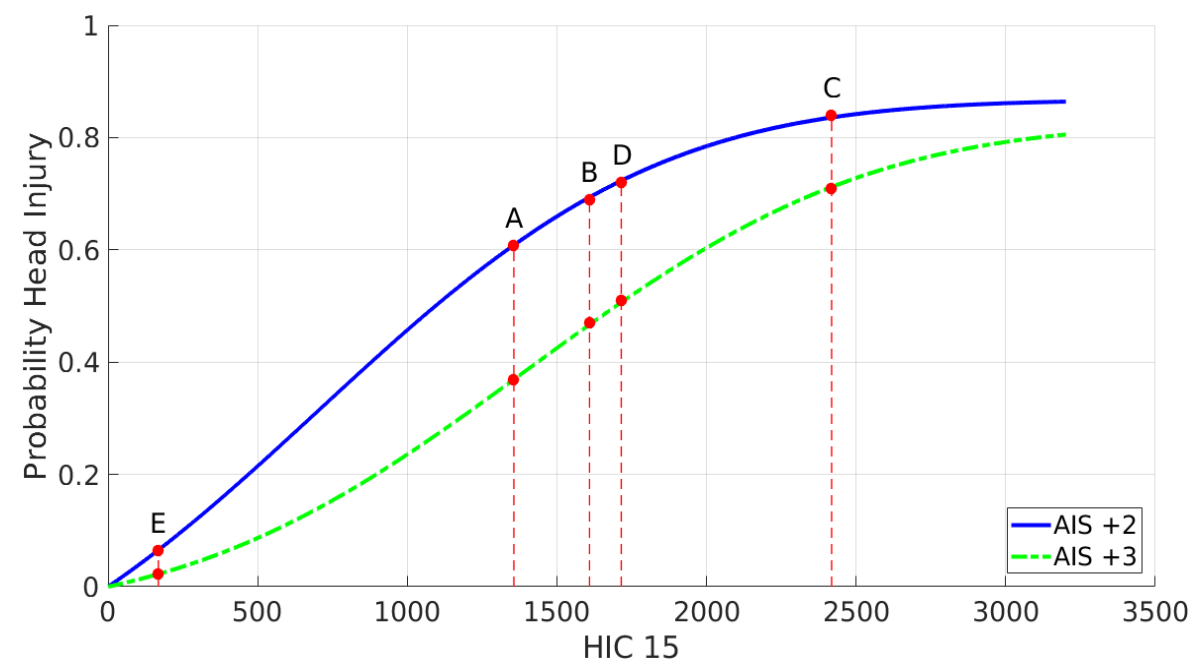

Figure 11 Correlation between head injury $\left(\mathrm{HIC}_{15}\right)$ and the probability of $\mathrm{AIS}+2$ and $\mathrm{AIS}+3$ injury on the abbreviated injury scale (AIS) for cases A, B, C, D and E.



Figure 12 Probability of skull fracture as a function of the skull fracture correlate (SFC), for cases A, B, C, D and E.

Table 3 presents the model criteria values for the four cases $(A, B, C, D)$, compared with the results of case $E$, when the driver had both hands on the steering wheel.

Table 3 Head injury criteria and probabilities in the 4 cases (A, B, C and D) compared with case E.

\begin{tabular}{cccccc}
\hline & HIC $_{\mathbf{1 5}}$ & SFC (g) & SFC (\%) & AIS+2 (\%) & AIS+3 (\%) \\
\hline Case A & 1.512 & 265 & 93.2 & 67 & 44 \\
\hline Case B & 1.609 & 246 & 89.1 & 69 & 45 \\
\hline Case C & 2.418 & 289 & 96.4 & 85 & 69 \\
\hline Case D & 1.715 & 267 & 94.2 & 72 & 50 \\
\hline Case E & 168 & 42 & 0.012 & 0.018 & 0.007 \\
\hline
\end{tabular}

Table 3 shows that case A, where the driver places the right hand between 2 and 3 o'clock and the left remains near the horn at the center of the steering wheel, the head injury criterion value $\left(\mathrm{HIC}_{15}\right)$ is 1512 . This is 9 times higher than 
that observed in case $E$, where both hands are on the wheel. The $\mathrm{HIC}_{15}$ values of the remaining cases (B, C and $\left.D\right)$ are even higher than that obtained for case $A$.

The values calculated for $\mathrm{HIC}_{15}$ demonstrate that the driver would sustain head injury in all the cases, given that the values are dangerously higher than the tolerable acceleration limits. In descending order, the most dangerous was case $C$, with high levels and percentage of moderate injuries, followed by $D, B$ and $A$, the least dangerous.

With respect to the skull fracture correlate (SFC), the lowest value was $246 \mathrm{~g}$ for case B, which is approximately 6 times higher than that of case $\mathrm{E}$. These results confirm that driver head injuries are always more serious when they drive with one hand.

The graph in figure 13 is an indicator of neck injury ( $\mathrm{Nij}$ ), based on a linear combination of critical axial force and the critical neck bending moment. These values form the geometric formation of critical values proposed by Prasad and Daniel in the book of A. Nahum and J. Melvin [33]. This geometric figure includes the combined modes of tensionextension, tension-flexion, compression-extension and compression-flexion neck loading.

The data points of the simulation inside the geometric formation, such as cases $A, D$ and $E$, meet the maximum tolerance criteria for neck loading. Cases B and C exceed these tolerable loads and are therefore considered the most injurious.

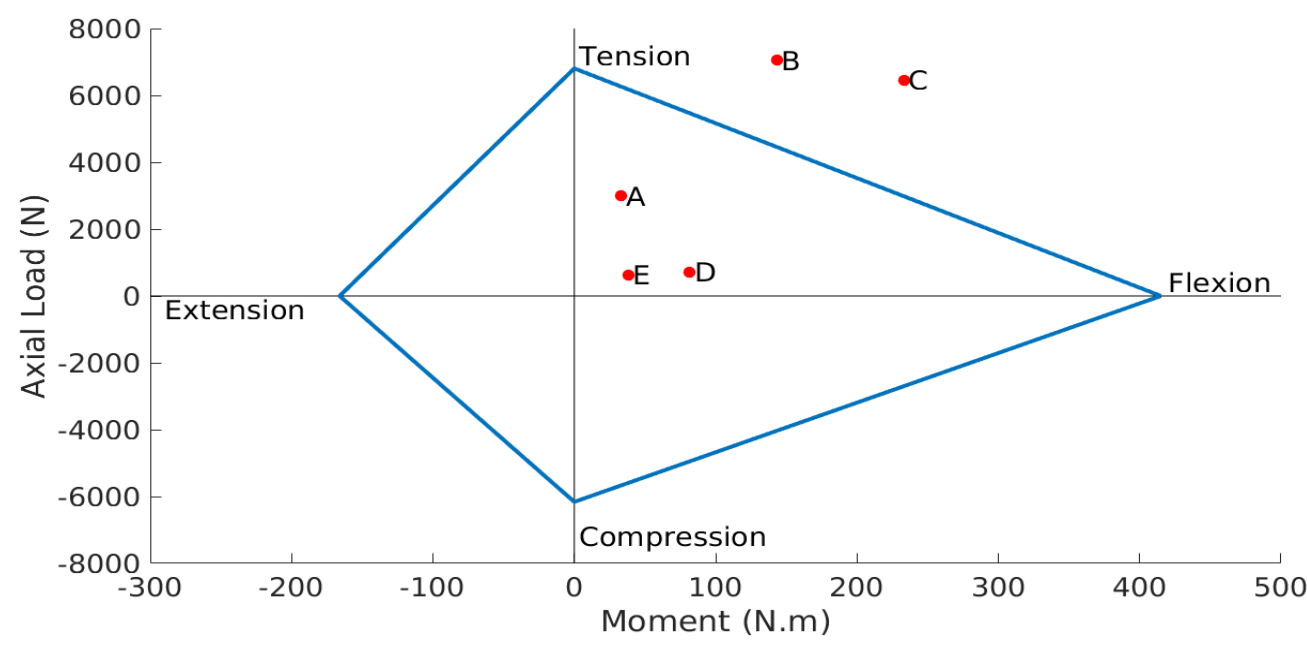

Figure 13 Axial load x moment (Nm). Nij criterion.

The combination of most representative forces is tension-flexion. Since the Hybrid III $50^{\text {th }}$ percentile male crash test dummy was used in the present study, the following critical tension-flexion values (Nij=Ntf) were recorded in the neck: tension of $6.806 \mathrm{~N}$ and flexion of $310 \mathrm{Nm}$. Table 4 shows the results obtained for $\mathrm{Ntf}$, using equation 10.

Table 4 Results for the Nij criterion and the probability of neck injury in the 4 cases compared with case E, for model 1.

\begin{tabular}{cccc}
\hline & $\mathbf{N}_{\mathrm{ij}}$ & AlS+2 (\%) & AlS+3 (\%) \\
\hline Case A & 0,60 & 20 & 10 \\
\hline Case B & 1,50 & 41 & 40 \\
\hline Case C & 1,70 & 46 & 48 \\
\hline Case D & 0,52 & 18 & 10 \\
\hline Case E & 0,38 & 16 & 7 \\
\hline
\end{tabular}

Table 4 shows that case $B$ and $C$ values for the neck exceed the limit suggested by the guideline, while cases $A$ and $D$ remained within the tolerance values of the crash dummy.

Figure 14 exhibits the probabilities of AIS +2 and AIS +3 neck and cervical spine injuries, considering the combined Ntf. injury criterion. 


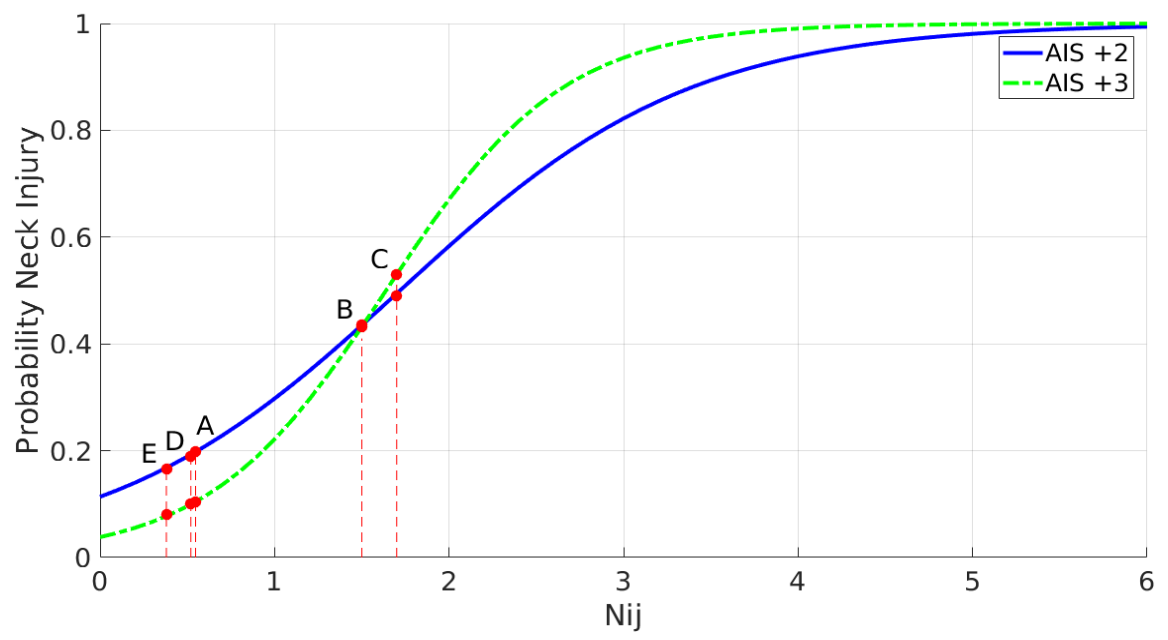

Figure 14 Nij risk curves for AIS+2 and AIS+3 injuries for cases A, B, C, D and E.

\section{6- Conclusions}

Validation of the simulated model showed that the simulation response was within the range (confidence interval) created based on NHTSA tests. The entrance function of acceleration was selected as input pulse for the simulation, obtaining overall vehicle behavior during the frontal impact. This function and the other simulation results were filtered using a fourth-order Butterworth filter implemented in MATLAB.

The analyses obtained in the head and neck injury simulations at all four positions assessed, where the driver used only one hand to steer, demonstrated the high risk of serious injury when their hands were not in the correct position for complete control of the moving vehicle. All the cases of driving with one hand (A, B, C and D) resulted in more severe injuries than when the driver was in the standard position (case $E$ ), with both hands on the wheel.

The results obtained in the simulation of the four cases of driving with only one hand demonstrate a probability of more than $67 \%$ that the driver will sustain AIS 2 injuries during a frontal crash, which may lead to moderate facial injuries. These cases also showed a greater than $44 \%$ probability of serious AIS +3 injury, resulting in facial skeleton fractures. The skull fracture correlate (SFC), calculated for the four cases, produced more specific findings on skull damage during the collision.

In all the cases, the skull fracture percentage was the most representative, occurring between 89 and $94 \%$ of cases where the driver had only one hand on the steering wheel. These values represent a high likelihood of death caused by injuries received when the hand that was not on the steering wheel struck the driver's head during the collision.

In regard to neck damage, the combined Nij criterion showed that the most serious injuries were tension-flexion of the neck during the collision and impact between the hand and head, for cases B and C. In these cases, the probability of injury was more than $40 \%$ in AIS+2 and AIS+3, which would result in serious spinal cord injuries during the frontal collision.

The analyses conducted on the driver's head and neck injuries, based on the data generated in frontal crash simulations, demonstrated that the passive protection available in the vehicle assessed was unable to effectively protect drivers if they were steering with only one hand. The severity of these injuries is significantly greater than that observed in drivers steering the same vehicles with both hands, in the standard position (case E).

Author's contributions: Conceptualization, Karen Viviana Pérez Luján, Cosme Roberto Moreira da Silva; Methodology, Karen Viviana Pérez Luján, Diego Antonio Legarda Cordoba; Writing - original draft, Karen Viviana Pérez Luján, Cosme Roberto Moreira da Silva; Writing - review \& editing, Karen Viviana Pérez Luján, Cosme Roberto Moreira da Silva, Palloma Vieira Muterlle, José Alexander Araújo, Jorge Luiz de Almeida Ferreira, Rita de Cassia Silva, Alessandro Borges de Souza Oliveira; Funding acquisition, Cosme Roberto Moreira da Silva; Resources, Cosme Roberto Moreira da Silva; Supervision, Cosme Roberto Moreira da Silva.

Editor: Marcílio Alves. 


\section{References}

[1] J. Holtz et al., "Crashworthiness enhancement of a composite intensive, multimaterial fully- electric urban car," pp. 1-6, doi: 10.1049/cp.2016.0978.

[2] H. M. Hassan, M. Shawky, M. Kishta, A. M. Garib, and H. A. Al-Harthei, "Investigation of drivers' behavior towards speeds using crash data and self-reported questionnaire," Accid. Anal. Prev., vol. 98, pp. 348-358, 2017, doi: 10.1016/j.aap.2016.10.027.

[3] M. Osman, R. Paleti, S. Mishra, and M. M. Golias, "Analysis of injury severity of large truck crashes in work zones," Accid. Anal. Prev., vol. 97, pp. 261-273, 2016, doi: 10.1016/j.aap.2016.10.020.

[4] J. R. Treat et al., "Tri-level Study of the Causes of Traffic Accidents," Dep. Transp. United States Am., 1979.

[5] S. G. Klauer et al., "The Impact of Driver Inattention On Near Crash/Crash Risk: An Analysis Using the 100-Car Naturalistic Driving Study Data," Analysis, no. April, p. 226, 2006, doi: DOT HS 810594.

[6] National Traffic Law Center, "Investigation and Prosecution of Distracted Driving Cases," 2017, doi: DOT HS 812407.

[7] C. M. Wickens, M. E. Toplak, and D. L. Wiesenthal, "Cognitive failures as predictors of driving errors, lapses, and violations," Accid. Anal. Prev., vol. 40, no. 3, pp. 1223-1233, 2008, doi: 10.1016/j.aap.2008.01.006.

[8] P. D. Bois, C. C. Chou, B. B. Fileta, A. I. King, and H. F. Mahmood, "Vehicle crashworthiness and occupant protection," Am. Iron Steel Inst., p. 372, 2004.

[9] R. Eppinger et al., "Development of Improved Injury Criteria for the Assessment of Advanced Automotive Restraint Systems - II By," no. November, 1999.

[10] W. N. Hardy, T. B. Khalil, and A. I. King, "Literature review of head injury biomechanics," Int. J. Impact Eng., vol. 15, no. 4, pp. 561-586, 1994, doi: 10.1016/0734-743X(94)80034-7.

[11] G. W. Nyquist, P. C. Begman, A. I. King, and H. J. Mertz, "Correlation of field injuries and GM hybrid III dummy responses for Lap-shoulder Belt Restraint,” J. Biomech. Eng., vol. 102, no. 2, pp. 103-109, 1980, doi: 10.1115/1.3138204.

[12] A. S. Mclntosh and D. A. Patton, "Boxing headguard performance in punch machine tests," Br. J. Sports Med., vol. 49 , no. 17, pp. 1108-1112, 2015, doi: 10.1136/bjsports-2015-095094.

[13] N. Li, H. Fang, C. Zhang, M. Gutowski, E. Palta, and Q. Wang, "A numerical study of occupant responses and injuries in vehicular crashes into roadside barriers based on finite element simulations," Adv. Eng. Softw., vol. 90, pp. 22-40, 2015, doi: 10.1016/j.advengsoft.2015.06.004.

[14] D. Otte, Comparison and Realism of Crash Simulation Tests and Real Accident Situations for the Biomechanical Movements in Car Collisions. SAE International, 1990.

[15] T. L. Teng, F. A. Chang, Y. S. Liu, and C. P. Peng, "Analysis of dynamic response of vehicle occupant in frontal crash using multibody dynamics method," Math. Comput. Model., 2008, doi: 10.1016/j.mcm.2007.10.020.

[16] Y. Zhang, C. Ju, G. Yue, X. Chen, and H. Sun, "Simulation analysis of the rear seat female in front impact," Proc. - $20123 r d$ Int. Conf. Digit. Manuf. Autom. ICDMA 2012, pp. 767-770, 2012, doi: 10.1109/ICDMA.2012.181.

[17] M. U. Khan and M. Moatamedi, "A review of airbag test and analysis," Int. J. Crashworthiness, vol. 13, no. 1, pp. 67-76, 2008, doi: 10.1080/13588260701731674.

[18] M. B. Panzer, J. B. Fice, and D. S. Cronin, "Cervical spine response in frontal crash," Med. Eng. Phys., vol. 33, no. 9, pp. 1147-1159, 2011, doi: 10.1016/j.medengphy.2011.05.004.

[19] R. Ge, M. Hu, and D. Xu, "Simulation study of safety belt restraint system in emergency brake," Proc. - 2012 5th Int. Conf. Intell. Comput. Technol. Autom. ICICTA 2012, pp. 619-622, 2012, doi: 10.1109/ICICTA.2012.160.

[20] X. Luo, W. Du, and J. Zhang, "Safety benefits of belt pretensioning in conjunction with precrash braking in a frontal crash," 2015, doi: 10.1109/IVS.2015.7225794.

[21] R. Razaghi, H. Biglari, M. Hasani, and A. Karimi, "Comparative numerical study on the child head injury under different child safety seat angles," Theor. Appl. Mech. Lett., vol. 9, no. 4, pp. 260-263, 2019, doi: 10.1016/j.taml.2019.04.005. 
[22] R. S. Happee R. Nayef A., Morsink P., de Lange R., Bours R., van Hoof and J., "Mathematical human body models representing a mid size male and a small female for frontal, lateral and rearward impact loading," Ircobi, vol. 2000 a, no. September, pp. 1-18, 2000.

[23] “NHTSA," 2020. www.nhtsa.org.

[24] P. Moreira, P. Flores, and M. Silva, "A biomechanical multibody foot model for forward dynamic analysis," 2012 IEEE 2nd Port. Meet. Bioeng. ENBENG 2012, 2012, doi: 10.1109/ENBENG.2012.6331396.

[25] I. Hogan, W. Manning, and J. D. Building, "The Use of Vehicle Dynamic Control Systems for Automotive Collision Mitigation."

[26] F. B. (U. S. D. of T. N. H. T. S. A. O. of C. S. Janovicz, Donna, "Final Report of New Car Assessment Program Frontal Impact Testing of 2013 Toyota Venza," 2013.

[27] TASS, “Design, Simulation and Virtual Testing (joints)," MADYMO Util. Man., 2013.

[28] TASS, “Design, Simulation and Virtual Testing (airbag, belt, model)," MADYMO Util. Man., 2013.

[29] TASS, “Design, Simulation and Virtual Testing (commands)," MADYMO Util. Man., 2013.

[30] TASS, “Design, Simulation and Virtual Testing (cinematic)," MADYMO Util. Man., pp. 5-7, 2013.

[31] T. International, “Objective Rating Help Manual," 2015. http://0eca4fe331aaaa0387ab39017777f15f755539d3047328d4a990.r16.cf3.rackcdn.com/downloads/MADYMO manuals/ObjectiveRating/html/index.html.

[32] O. C. Protection, W. Mounting, and W. Z. Intrusion, "NATIONAL HIGHWAY TRAFFIC SAFETY ADMINISTRATION LABORATORY TEST PROCEDURE FOR FMVSS 208, Occupant Crash Protection FMVSS 212, Windshield Mounting FMVSS 219, Windshield Zone Intrusion FMVSS 301F, Fuel System Integrity - Frontal," 2008.

[33] A. Nahum and J. Melvin, Accidental Injury. 2014.

[34] H. Henn, "Crash Tests and the Head Injury Criterion," Teach. Math. its Appl., vol. 17, no. 4, pp. 162-170, 1998, doi: 10.1093/teamat/17.4.162.

[35] P. Prasad and H. J. Mertz, "The Position of the United States Delegation to the ISO Working Group 6 on the Use of HIC in the Automotive Environment," no. January 1985, 1985, doi: 10.4271/851246.

[36] M. Vander Vorst, J. Stuhmiller, K. Ho, N. Yoganandan, and F. Pintar, "Statistically and biomechanically based criterion for impact-induced skull fracture.," Annu. Proc. Assoc. Adv. Automot. Med., vol. 47, pp. 363-81, 2003.

[37] P. Chan et al., "Development Of Generalized Linear Skull Fracture Criterion," 20th Int. Tech. Conf. Enhanc. Saf. Veh., pp. 111, 2007, doi: 10.1017/СB09781107415324.004.

[38] Workgroup Data Processing Vehicle Safety, “Crash Analysis Criteria Description,” Data Process., no. May, 2008.

[39] K. Reif, Fundamentals of Automotive and Engine Technology. 2014.

[40] W. Hollowell, H. Gabler, S. Stucki, S. Summers, and J. Hackney, "Updated review of potential test procedures for FMVSS No.208," p. 110, 1998, [Online]. Available: https://www.nhtsa.gov/sites/nhtsa.dot.gov/files/nprm_208.pdf. 